\title{
Identifying the root causes for inventory accumulation and prioritizing them using an MCDM-based TOPSIS approach
}

\author{
Lakshman Singh Negi and Yashomandira Kharde \\ Symbiosis Institute of Operations Management, Symbiosis International University, \\ Nashik, India
}

Invetory accumulation and its priotization
Received 27 November 2020 Revised 2 April 2021 6 May 2021 Accepted 31 May 2021

\begin{abstract}
Purpose - Inventory accumulation is a major problem for any organization, as it not only occupies the valuable storage space, but it also blocks the company's capital, leaving the owners with less cash to run the company's business. Aggregation of inventory in any organization contributes to inventory carrying cost; it affects labor productivity, increases equipment expenses and creates a loss of opportunity associated with it. Therefore, it is essential for any organization to come up with a solution to deal with the stockpile of inventory. Design/methodology/approach - This research aims to examine the potential causes of inventory aggregation in an organization. First, the potential factors for the build-up of inventory are identified from survey data collection, such as questionnaire approach and discussion with industry experts, and then weights are assigned to attributes to study the effects for these factors. After the identification of probable causes, they are analyzed through a multi-criterion decision-making (MCDM) approach and the technique for order of preference by similarity to ideal solution (TOPSIS) to prioritize the severity of these causes toward the accumulation of inventory and take corrective actions to prevent their disruptive effect on the business.

Findings - The top three causes identified from the TOPSIS analysis are sales and forecasting error, defects and quality related issues and communication gap between departments. Firstly, we focus on these major contributors and prioritize them using the TOPSIS analysis. Then, we proceed further toward other factors. The main reasons identified for the accumulation of inventory are (1) forecasting error, (2) bulk purchase, (3) data entry error, (4) communication gaps, (5) quality-related issues, (6) product category not traceable and (7) wrong material being procured.

Research limitations/implications - To carry out the data analysis in this research paper, first survey data collection is done. Then, discussions with managers and executives in the particular domain are carried out, and weights are assigned to the attributes and the criteria to study the effects of the identified factors. After that root cause analysis (RCA) is performed to get to the genesis of the problem and to take necessary corrective action, for carrying out this study, a total of seven potential causes were identified and the contribution of these seven causes on five attributes or criteria, i.e. quantity (in tons), holding and carrying cost, effect on labor productivity, loss of opportunity cost and storage space were studied.

Originality/value - This research paper is the author's original work, and all the analyses carried out are from the discussion with experts in the field and through the in-depth analysis carried out. This research aims to examine the potential causes of the accumulation of inventory in organizations and their contribution toward factors like inventory carrying cost, labor productivity, and opportunity loss and excessive storage space have been analyzed. This research provides great value to the readers in the respective domain.
\end{abstract}

Keywords Root cause analysis (RCA), Slow-moving inventory (SMI), Non-moving inventory (NMI), Dead stock, Multi-criteria decision-making (MCDM), TOPSIS, Ideal best solution, Ideal worst solution, Euclidean distance

Paper type Research paper

(C) Lakshman Singh Negi and Yashomandira Kharde. Published in Modern Supply Chain Research and Applications. Published by Emerald Publishing Limited. This article is published under the Creative Commons Attribution (CC BY 4.0) license. Anyone may reproduce, distribute, translate and create derivative works of this article (for both commercial and non-commercial purposes), subject to full attribution to the original publication and authors. The full terms of this license may be seen at http:// creativecommons.org/licences/by/4.0/legalcode

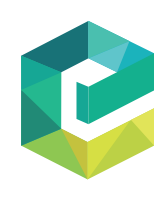

Modern Supply Chain Research and Applications Vol. 3 No. 2, 2021 pp. $145-154$

Emerald Publishing Limited DOI 10.1108/MSCRA-11-2020-0031 
MSCRA

3,2

146

\section{Introduction}

Accumulation of inventory is a serious issue for any organization, as it occupies the valuable storage space that is generally limited, and it also blocks your capital for an organization. This generation of inventory starts with the arrival of slow-moving inventory (SMI) and goes on to take the shape of non-moving inventory (NMI). If for finished goods or semi-finished goods, the product category remains in inventory for more than 30 days, it is considered to be a slow-moving category, and if the duration for the same exceeds 60 days, it is considered to be non-moving inventory (NMI). In the case of raw material and purchase material, if the duration for the product category in inventory is more than 60 days, it is considered to be SMI, and if the duration exceeds 90 days, it is considered as NMI (see Table 1).

Excessive inventory in any organization is harmful and generally contributes toward high inventory carrying cost, affecting your labor productivity, increment in equipment expenses and loss of opportunity associated with it. Therefore, it is crucial for any company to come up with a way out to deal with this inventory accumulation.

For a finished good, if the duration of the product category in inventory is from 6 to 9 months, $50 \%$ provision associated with product type is considered to be lost; if the duration is from 9 to 12 months, $75 \%$ provision is considered to be lost, and if the duration exceeds 12 months, $100 \%$ provision is considered to be lost. For semi-finished goods, if the duration of product kind in inventory exceeds 6 months, $100 \%$ provision is considered to be lost. In the case of raw material and purchase material, if the duration of the product category in inventory is from 9 to 12 months, $25 \%$ provision associated with the product type is considered to be lost. If the duration is from 12 to 18 months, $50 \%$ provision is considered to be lost. If the duration is greater than 18 months, $100 \%$ provision is considered to be lost (see Table 2).

There are a number of reasons involved for a product group, such as raw material, finished goods or semi-finished goods, to become a part of a slow-moving one and finally accumulating in your inventory as NMI. Few of the reasons identified from the discussion with the managers and industry experts are listed below:

(1) Forecasting error - In order to become more responsive to customer demand in the competitive market, organizations over-forecast in the anticipation of demand, and if the order is not received as per the projections, it leads to SMI.

(2) Bulk purchase - In order to take advantage of the discount associated with the bulk purchase or for taking price benefit from the order, certain regular material is being

\begin{tabular}{lcccc}
\hline Major group & $6-9$ months $\%$ & $9-12$ months $\%$ & $12-18$ months $\%$ & Greater than 18 months \\
\hline FG & 50 & 75 & $100 \%$ & 100 \\
SFG & 100 & 100 & 100 & 100 \\
RM & - & 25 & 50 & 100 \\
PM & - & 25 & 50 & 100
\end{tabular}

Table 2.

Percentages of cost provision lost with time duration
Product categorization into slow-moving and non-moving inventory

\begin{tabular}{lllll}
\hline Category & $0-30$ Days & 30-60 Days & $60-90$ Days & $90-180$ Days \\
\hline FG & Fresh & Slow-moving & Non-moving & Non-moving \\
SFG & Fresh & Slow-moving & Non-moving & Non-moving \\
RM & Fresh & Fresh & Slow-moving & Non-moving \\
PM & Fresh & Fresh & Slow-moving & Non-moving \\
\hline
\end{tabular}

RM
PM 
procured in a huge quantity than the actual requirement, leading to the generation of SMI in the system.

(3) Data entry error - If an error is made in entering the data, you do not have a proper stock estimate, and you go on procuring excess material, which leads to the accumulation of NMI. Such an error can occur due to reasons like the material is being consumed, but the entry is not done in the system, or the material is available in the stock, but the system does not show the same.

(4) Communication gaps - Due to a lack of communication among suppliers, planning team and marketing team, there is the procurement of wrong material or purchase of excessive material, which leads to the generation of SMI

(5) Quality related issues - This is either due to defects in the production, or if the customer rejects the product due to quality expectation not being met, then this material has to be stocked, and it creates NMI.

(6) Untraceable product category - If due to poor management, you are unable to track the material, and when an order related to the same arrives, you go on buying that extra material, and it creates NMI in the system.

(7) Wrong material being procured - Procuring the wrong part or the material from the supplier end leads to stocking of this material until the similar order arrives, which leads to NMI.

\section{Literature review}

In any manufacturing company, inventory can be categorized into three major types, i.e. raw material, work in process and finished good inventory, and each of these types requires appropriate inventory management techniques (Tsourveloudis et al., 2000; Rozhkov and Ivanov, 2018; Chuang and Zhao, 2019). Inventory management is an important aspect for any company in order to have an optimum inventory level, as excessive inventory can cost a company from about $20 \%$ to $40 \%$ of the total inventory value throughout the year, so it should be properly monitored and maintained at a minimal level (Ganeshan et al., 1999).

The categorization of inventory into slow-moving and non-moving varies from organization to organization, as it depends on the management policies, and types and characteristics of any company. Inventory that remains in warehouse beyond six months is considered as slow-moving, and the inventory stocked above one year is considered as nonmoving (Goh and Lim, 2014). Non-moving and slow-moving stocks have very low turnover ratios and are generally slow in their circulation and distribution volumes (Dolgui and Pashkevich, 2006; Pince and Dekker, 2011, Synder et al., 2012). Dead stock is considered as an unsold stock that is stored in the warehouse for a long period of time (Synder, 2002). This NMI leads to obsolescence of goods, and there is also a huge inventory carrying cost associated with it (Fan and Zhou, 2018; He and Wang, 2019). Various costs associated with poor inventory levels are labor cost, equipment expenses, maintenance cost, insurance premiums, and opportunity cost and cost of material detention (Hiller and Lieberman, 2017).

Considering the past researchers on slow-moving and non-moving inventory levels, it is evident that the major reason for the stockpile of inventory is accumulation on the basis of anticipation of demand (Matsebatlela and Mpofu, 2015; Escalona et al., 2019), seasonality of the product (Panda et al., 2008), low-demand pattern (Mobarakeh et al., 2017; Petropoulos et al., 2019), manufacturing- or quality-related issues (Fan and Zhou, 2018) and lack of monitoring on low turnover stocks (Chuang and Zhao, 2019). Holding the MNI and dead stock for a longer duration will definitely lead to a significant amount of cost to an organization in terms of loss of investment opportunities, the non-value-added cost in storing and managing the items and 
MSCRA

3,2

148

increment in the management costs (He and Wang, 2019). As the stockpile of unnecessary inventory creates additional non-value-added costs, it should be minimized and organization should focus on having an optimum level of inventory in their warehouses (Tayyab and Sarkar, 2016). So, it is necessary for any organization to have an optimum inventory level in order to deal with uncertainty in the demand pattern (Nemtajela and Mbohwa, 2017; Chuang and Zhao, 2019), unreliability from the supplier's side (Jaarsveld and Dekker, 2011), a quantity discount and a lower ordering cost (Cardenas-Barron et al., 2020; He and Wang, 2019).

This research provides valuable insight and a way to tackle the problem of inventory buildup in an organization. Using the data analysis approach depicted in this paper, one can easily minimize the impact of inventory accumulation in an organization by first focusing on few of the major contributors and then moving the focus toward lesser contributors. Companies should focus on implementing a just-in-time approach and process innovation in order to minimize the harmful effect of inventory accumulation and avoiding dead stocks (Pince and Dekker, 2011; Van Jaarsveld and Dekker, 2011). So, this research focuses on analyzing the root causes for inventory aggregation in an organization and prioritizing the same in order to take necessary corrective actions. For prioritizing the causes, we use a multicriterion decision-making approach, i.e. TOPSIS, which was first proposed by (Hwang and Yoon, 1981) as a method for ranking the alternatives on the basis of attributes or criteria and calculating the Euclidean distance from the ideal solution. This technique was later developed by many researchers (Jahanshahloo et al., 2006) who presented steps and procedures for doing the TOPSIS analysis for multi-criteria decision-making. In the case of the qualitative attribute, we convert it to quantitative terms using a linguistic variable rating point scaling system, which varies from one to nine (Jadidi et al., 2008a, b).

\section{Root cause analysis (RCA)}

Root cause analysis has been carried out to examine the probable causes in a more detailed manner. With the RCA analysis, the reasons for the stockpile of inventory have been considered in a more detailed fashion. Several reasons that were identified from the survey data collection were drilled down further to get to the roots of the problem. After getting to the reasons for the probable causes, certain corrective actions have been suggested, and recommendations were provided to improve the same.

\section{Methodology}

From the survey data collection and discussions with managers and executives working in the various organizations, firstly, the potential causes of the generation of SMI were identified, and then reasons were studied for how these get converted to NMI. After further study respective weights were assigned to attributes and criteria to analyze the effects for each of the potential identified factors.

To start with this study, a total of seven potential causes were identified from discussions with the industry experts. Then, the effects of each of these factors on the identified attributes were studied. The attributes identified are inventory carrying cost, excessive storage space required, the cost associated with a loss of opportunity, quantity in tons and effect on labor productivity; these attributes were assigned weights of $0.30,0.20,0.15,0.20,0.15$, respectively. After identification of the potential causes and their respective contribution toward the generation of SMI and NMI, an MCDM tool, i.e. TOPSIS, is being employed to prioritize the severity of these causes toward the accumulation of NMI. For carrying out our analysis through TOPSIS, six main steps were followed as shown below:

Step 1: Firstly, we go on formulating a normalized decision matrix.

Step 2: After that. we form a weighted normalized decision matrix. This is done by multiplying each of the performance score by respective weights of the criteria. 
Step 3: Then, we go on identifying the ideal best, i.e. $P_{j^{+}}$and ideal worst i.e. $P_{j^{-}}$solution.

Step 4: Then, we identify Euclidean distance from ideal best, i.e. $V_{i^{+}}$and ideal worst, i.e. $V_{i^{-}}$ solution.

Step 5: After that, we calculate the performance score, i.e. $X_{i \text {. }}$

Step 6: Then, go on ranking the potential causes based on their performance score.

\section{Invetory accumulation and its priotization}

\section{Data analysis}

To start with the prioritization of the potential cause using an MCDM approach, i.e. TOPSIS, we first gathered the performance value for each of the identified causes from survey data analysis using a questionnaire approach and discussion with the industry experts. So, Table 1, shown below, denotes the performance value for causes with respect to attributes and is denoted by $S_{i j}$ (see Table 3 ).

To give the scores to the qualitative values, for which the expression in number format is difficult, we use a linguistic rating scale that varies from one to nine, as shown in Figure 1. So, this helps us to convert the qualitative values into the quantitative format (see Figure 2).

When we have completed the performance table by giving the score to each attribute, we go on finding the normalized decision matrix; this is done by dividing each of the performance scores with respective rooted summation of square values, and the formulae used for the same is depicted below:

$$
\overrightarrow{S_{i j}}=\frac{S_{i j}}{\sqrt{\sum_{i=1}^{n} S_{i j}^{2}}}
$$

After arriving at the normalized decision matrix, we give weightages to each of the identified attributes according to the effect potential causes have on them, and we then proceed further to arrive at the weighted normalized decision matrix (see Table 4).

\section{Normalized decision matrix}

For calculating the weighted normalized decision matrix, we first calculate $P_{j^{+}}$and $P_{j^{-}}$, which denotes ideal best and ideal worst solution, respectively, and we then find out $V_{i^{+}}$and $V_{i^{-}}$,

\begin{tabular}{|c|c|c|c|c|c|c|}
\hline Causes & $\begin{array}{l}\text { Carrying } \\
\text { cost (Rs) }\end{array}$ & $\begin{array}{l}\text { Excess storage } \\
\text { space }\end{array}$ & $\begin{array}{c}\text { Effect } \\
\text { Loss of } \\
\text { opportunity cost }\end{array}$ & $\begin{array}{l}\text { Quantity } \\
\text { (tons) }\end{array}$ & $\begin{array}{l}\text { Effect on labor } \\
\text { productivity }\end{array}$ & \\
\hline Forecasting error & 400,000 & 9 & 7 & 120 & 7 & \\
\hline Bulk purchase & 100,000 & 7 & 5 & 70 & 8 & \\
\hline Data entry error & 150,000 & 5 & 6 & 40 & 8 & \\
\hline $\begin{array}{l}\text { Communication } \\
\text { gaps }\end{array}$ & 90,000 & 8 & 7 & 75 & 6 & \\
\hline Quality Issues & 300,000 & 8 & 8 & 50 & 9 & \\
\hline $\begin{array}{l}\text { Untraceable } \\
\text { material }\end{array}$ & 150,000 & 6 & 7 & 55 & 8 & \\
\hline $\begin{array}{l}\text { Wrong material } \\
\text { procured }\end{array}$ & 100,000 & 7 & 8 & 65 & 7 & $\begin{array}{r}\text { Table } 3 . \\
\text { The performance score }\end{array}$ \\
\hline $\begin{array}{l}\text { Rooted sum of } \\
\text { sq. values }\end{array}$ & 568418.86 & 19.18 & 18.33 & 190.46 & 20.17 & $\begin{array}{r}\text { for probable causes } \\
\text { wrt attributes }\end{array}$ \\
\hline
\end{tabular}


MSCRA

3,2

150

Figure 1.

RCA for the potential causes leading to inventory accumulation
Figure 2.

A linguistic scale for conversion into quantitative figures

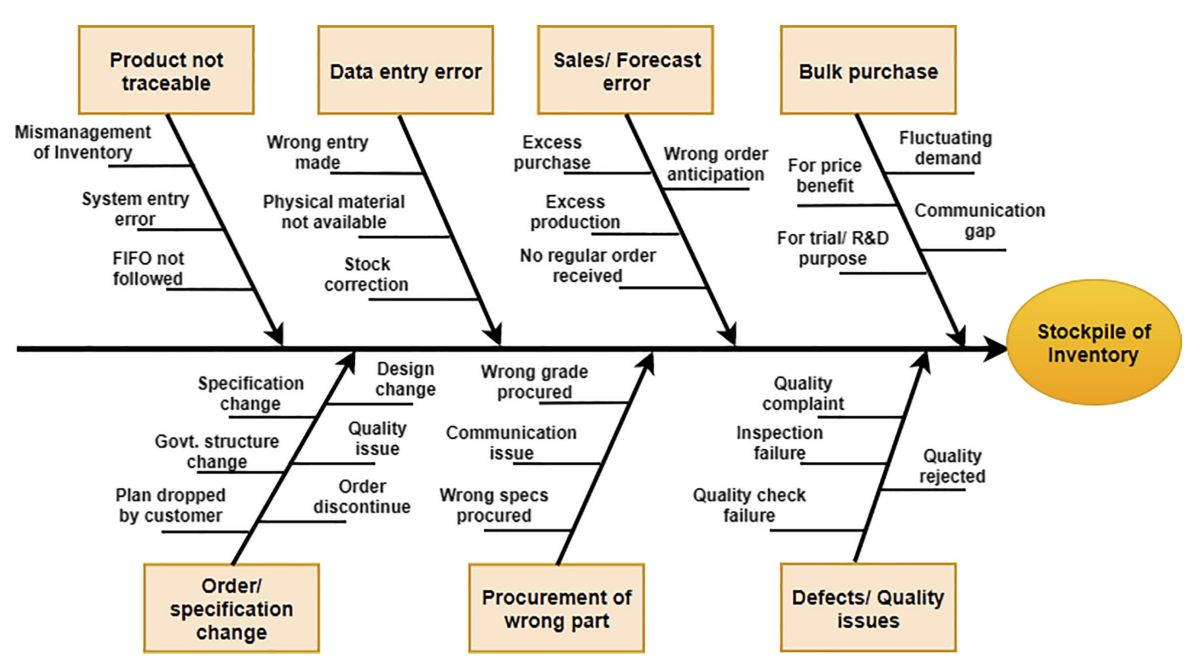

\begin{tabular}{|c|c|}
\hline 1 & Very Low \\
\hline 3 & Low \\
\hline 5 & Moderate \\
\hline 7 & High \\
\hline 9 & Very High \\
\hline $2,4,6,8$ & Intermediate values \\
\hline
\end{tabular}

\begin{tabular}{|c|c|c|c|c|c|}
\hline Weights & 0.30 & 0.20 & 0.15 & 0.20 & 0.15 \\
\hline Causes & $\begin{array}{l}\text { Carrying } \\
\text { cost (Rs) }\end{array}$ & $\begin{array}{c}\text { Excess storage } \\
\text { space }\end{array}$ & $\begin{array}{c}\text { Effect } \\
\text { Loss of } \\
\text { opportunity cost }\end{array}$ & $\begin{array}{l}\text { Quantity } \\
\text { (tons) }\end{array}$ & $\begin{array}{c}\text { Effect on labor } \\
\text { productivity }\end{array}$ \\
\hline Forecasting error & 0.704 & 0.469 & 0.382 & 0.630 & 0.347 \\
\hline Bulk purchase & 0.176 & 0.365 & 0.273 & 0.368 & 0.397 \\
\hline Data entry error & 0.264 & 0.261 & 0.327 & 0.210 & 0.397 \\
\hline $\begin{array}{l}\text { Communication } \\
\text { gaps }\end{array}$ & 0.158 & 0.417 & 0.382 & 0.394 & 0.297 \\
\hline Quality Issues & 0.528 & 0.417 & 0.436 & 0.263 & 0.446 \\
\hline $\begin{array}{l}\text { Untraceable } \\
\text { material }\end{array}$ & 0.264 & 0.313 & 0.382 & 0.289 & 0.397 \\
\hline $\begin{array}{l}\text { Wrong material } \\
\text { procured }\end{array}$ & 0.176 & 0.365 & 0.436 & 0.341 & 0.347 \\
\hline
\end{tabular}

which denotes the Euclidean distance from ideal best and ideal worst solution. To find out $V_{i^{+}}$ and $V_{i^{-}}$, we use the following formulas:

$$
V_{i^{+}}=\sqrt{\sum_{i=1}^{n}\left(P_{j^{+}}-P_{i j}\right)^{2}}
$$




$$
V_{i^{-}}=\sqrt{\sum_{i=1}^{n}\left(P_{j^{-}}-P_{i j}\right)^{2}}
$$

Invetory accumulation and its

After finding $V_{i^{+}}$and $V_{i^{-}}$, we go on calculating the performance score, which is denoted by $X_{i}$ priotization (see Table 5).

Weighted normalized decision matrix

So, for calculating the performance score $X_{i}$, we use the following formula:

$$
X_{i}=\frac{\left(V_{i^{+}}\right)}{\left(V_{i^{-}}\right)+\left(V_{i^{+}}\right)}
$$

After arriving at the performance score, we go on ranking the alternatives and prioritizing them to find out the major contributor for the generation of SMI and NMI.

\section{Managerial implications}

This research contributes a significant help to managers in overcoming the harmful effects of inventory accumulation in the company. The study also focuses on providing insights that quite a few resources are increasing cost to the organization without adding any value to the company. In addition, this study provides managers a solution to effectively identify the build-up of NMI at an early stage and take necessary actions. Aggregation of inventory leads to high non-value-added costs such as warehouse cost, maintenance cost, repair cost and loss of opportunity.

\section{Results}

The results depict that the inventory build-up in any organization is due to a variety of factors, such as forecasting error, quality-related issues, wrong procurement, bulk purchase, communication gaps, etc. Using this model, one can easily find out the major contributor to the accumulation of inventory and can prioritize the same in order to take necessary actions on them. The ranking of the potential causes through the TOPSIS analysis is completely based on the performance score table that is obtained from feedback and suggestions of experts in the respective domain. To reduce the non-moving and dead inventory, we have to monitor our current system and try to develop human resource capabilities by focusing more on information technology solutions.

\section{Conclusions}

This research focuses on exploring the possible solutions that an organization can follow in order to reduce its inventory accumulation issues. The limitation of this research is that it is confined to non-moving and SMI only. Thus, future research may be expanded to include all types of inventories, along with the cost associated with them. In order to reduce the stockpile of inventory, certain corrective actions and preventive measures should be taken care of. Defective or quality rejected material should be immediately scrapped or sold as disposal. You should regularly review your forecast to avoid unnecessary build-up of inventory. Inventory methods, such as FIFO, should be followed to keep track of the inventory pattern. Bulk purchases for discount opportunity should be avoided, as it leads to excessive inventory. In the case of order or specifications change from the customer end, the committed material should be immediately consumed in some other processes considering little wastage.. Data entry in the system should be done in a timely and error-free manner, as it 
MSCRA

3,2

152

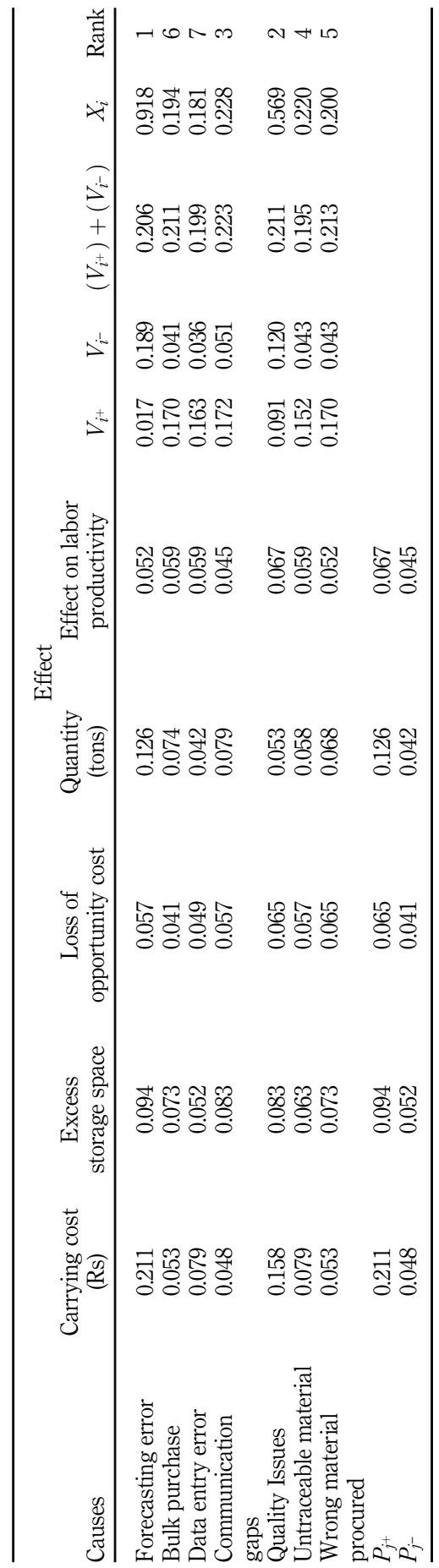

Table 5.

The weighted normalized decision matrix 
helps to get a proper estimate of the inventory levels. The production and warehouse staff should be aware of the harmful effects of inventory aggregation and also the cost associated with it. Thus, by analyzing all these aspects, it is possible for an organization to reduce the build-up of inventory levels.

\section{References}

Cárdenas-Barrón, L., Shaikh, A., Tiwari, S. and Treviño-Garza, G. (2020), “An EOQ inventory model with nonlinear stock dependent holding cost, nonlinear stock dependent demand and trade credit", Computers and Industrial Engineering, Vol. 5, 105557.

Chuang, C.H. and Zhao, Y. (2019), "Demand stimulation in finished-goods inventory management: empirical evidence from general motors dealerships", International Journal of Production Economics, Vol. 208, pp. 208-220.

Dolgui, A. and Pashkevich, M. (2006), "Demand forecasting for multiple slow-moving items with low consumption and short requests history", International Journal of Production Economics, Vol. 39 No. 3, pp. 161-166.

Escalona, P., Angulo, A., Weston, J., Stegmaier, R. and Kauak, I. (2019), "On the effect of two popular service-level measures on the design of a critical level policy for fast-moving items", Computers and Operations Research, Vol. 107, pp. 107-126.

Fan, D. and Zhou, Y. (2018), "Operational safety: the hidden cost of supply-demand mismatch in fashion and textiles related manufacturers", International Journal of Production Economics, Vol. 198, pp. 70-78.

Ganeshan, R. (1999), "Managing supply chain inventories: a multiple retailer, one warehouse, multiple supplier model", International Journal of Production Economics, Vol. 59 Nos 1-3, pp. 341-354.

Goh, S.H. and Lim, B.L. (2014), "Centralizing slow-moving items in a retail network - a case study. International conference on industrial engineering and Operations management", Proceeding of 2014, Bali, January 7-9.

He, H. and Wang, S. (2019), "Cost-benefit associations in consumer inventory problem with uncertain benefit", Journal of Retailing and Consumer Services, Vol. 51, pp. 271-284.

Hillier, F. and Lieberman, G. (2017), Introduction to Operations Research, 10th ed., McGraw Hill, New York.

Hwang, C.L. and Yoon, K. (1981), Multiple Attribute Decision Making: Methods and Applications, Springer-Verlag, Berlin, Heidelberg, New York, NY.

Jadidi, O., Hong, T.S., Firouzi, F., Yusuff, R.M. and Zulkifli, N. (2008a), "TOPSIS and fuzzy multiobjective model integration for supplier selection problem", Journal of Achievements in Materials and Manufacturing Engineering, Vol. 31 No. 2, pp. 762-769.

Jadidi, O., Hong, T.S., Firouzi, F. and Yusuff, R.M. (2008b), "An optimal grey based approach based on TOPSIS concept for supplier selection problem”, International Journal of Management Science and Engineering Management, Vol. 4 No. 2, pp. 104-117.

Jahanshahloo, G.R., Lofti, F.H. and Izadikhah, M. (2006), "An algorithmic method to extend TOPSIS for decision making problems with interval data", Applied Mathematics and Computation, Vol. 175, pp. 1375-1384.

Matsebatlela, M.G. and Mpofu, K. (2015), "Inventory management framework to minimize supply and demand mismatch on a manufacturing organization”, IFAC-PapersOnLine, Vol. 48 No. 3, pp. 260-265.

Mobarakeh, N.A., Shahzad, M.K., Baboli, A. and Tonadre, R. (2017), "Improved forecasts for uncertain and unpredictable spare parts demand in business aircraft's with bootstrap method", IFACPapersOnLine, Vol. 50 No. 1, pp. 15241-15246.

Nemtajela, N. and Mbohwa, C. (2017), "Relationship between inventory management and uncertain demand for fast moving consumer goods organisations", Procedia Manufacturing, Vol. 8, pp. 699-706. 
MSCRA

3,2
Panda, S., Senapati, S. and Basu, M. (2008), "Optimal replenishment policy for perishable seasonal products in a season with ramp-type time dependent demand", Computers and Industrial Engineering, Vol. 54 No. 2, pp. 301-314.

Petropoulos, F., Wang, X. and Disney, S.M. (2019), "The inventory performance of forecasting methods: evidence from the M3 competition data", International Journal of Forecasting, Vol. 35 No. 1, pp. 251-265.

Pince, C. and Dekker, R. (2011), "An inventory model for slow moving items subject to obsolescence”, European Journal of Operational Research, Vol. 213, pp. 83-95.

Rozhkov, M. and Ivanov, D. (2018), “Contingency production-inventory control policy for capacity disruptions in the retail supply chain with perishable products", IFAC-PapersOnLine, Vol. 51 No. 11, pp. 1448-1452.

Synder, R. (2002), "Forecasting sales of slow and fast moving inventories", European Journal of Operational Research, Vol. 140, pp. 684-699.

Synder, R.D., Keithord, J. and Beaumont, A. (2012), "Forecasting the intermittent demand for slow moving inventories: a modeling approach”, International Journal of Forecasting, Vol. 28, pp. 485-496.

Tayyab, M. and Sarkar, B. (2016), "Optimal batch quantity in a cleaner multi-stage lean production system with random defective rate”, Journal of Cleaner Production, Vol. 139, pp. 922-934.

Tsourveloudis, N.C., Dretoulakis, E. and Ioannidis, S. (2000), "Fuzzy work-in-process inventory control of unreliable manufacturing systems", Information Sciences, Vol. 127 No. 1, pp. 69-83.

Van Jaarsveld, W. and Dekker, R. (2011), "Estimating obsolescence risk from demand data to enhance inventory control - a case study”, International Journal of Production Economics, Vol. 133 No. 1, pp. $423-431$.

\section{Corresponding author}

Lakshman Singh Negi can be contacted at: lakshman.negi8@gmail.com

For instructions on how to order reprints of this article, please visit our website:

www.emeraldgrouppublishing.com/licensing/reprints.htm

Or contact us for further details: permissions@emeraldinsight.com 